\title{
Metals Doped CdS Quantum Dots: Structural, Optical and Photocatalytic Properties under Visible Light Irradiation
}

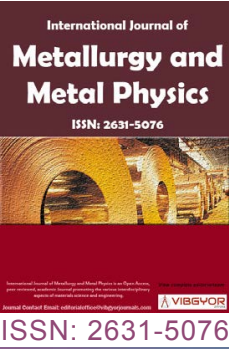

\section{Naziruddin Khan ${ }^{1 *}$, Abdullah Almohammedi', MA Majeed Khan ${ }^{2}$ and Muhammad Ali Shar ${ }^{2}$}

\author{
${ }^{1}$ Department of Physics, Faculty of Science, Islamic University, Saudi Arabia \\ ${ }^{2}$ King Abdullah Institute for Nanotechnology, King Saud University, Saudi Arabia
}

\begin{abstract}
Cadmium sulphide quantum dots (CdS-QDs) were obtained by a precipitation method. Studies on the structural, optical and photocatalytic properties of undoped and metals $(\mathrm{M}=\mathrm{Fe}$, $\mathrm{Ag}, \mathrm{Zn}$ ) doped $\mathrm{CdS}$ were investigated. The structural properties of the metals composite CdS were analyzed using X-ray diffraction (XRD) and Infrared (IR) techniques. Optical properties of the composite materials were characterized by absorption and photoluminescence techniques. XRD pattern reveals the undoped and metals doped QDs have highly crystalline in nature with cubic phases. High transmission electron microscopy (TEM) shows the spherical shape of particles with approximately 3-4 $\mathrm{nm}$ in sizes. The crystallite sizes of CdS are increased with doping of metals but slightly different the sizes of XRD and TEM images. The band gap values of $\mathrm{CdS}$, Fe:CdS, $\mathrm{Ag}: \mathrm{CdS}$, and $\mathrm{Zn}: \mathrm{CdS}$ calculated by Tauc plot are predicted as $3.64,3.50 \mathrm{eV}, 3.43$ and $3.35 \mathrm{eV}$ respectively. Upon doping metals, shift in band gap of QDs toward the longer wavelength with the increases of crystallite sizes is observed and depends on type of metals. The emission peak of QDs is appeared at $521 \mathrm{~nm}$ along with a shoulder at $430 \mathrm{~nm}$ which confirms of cadmium vacancies in the lattice. The emission intensity of QDs is decreased when metals are included. The emission peaks of metals doped QDs are gradually decreased over the increasing irradiation time and influenced by the nature of metal. The photo-catalytic activity and efficiency degradation are dependent of metals which may due to different crystal quality in $\mathrm{Ag}$, Fe and $\mathrm{Zn}$ into CdS QDs composite. Present results suggest that $\mathrm{Zn}: \mathrm{CdS}$ composite enhanced with superior photo-degradation efficiency and photo-catalytic activity under the sunlight.
\end{abstract}

\section{Keywords}

Metals composites CdS QDs, XRD, Structural, PL, Photo-catalytic, TEM

\section{Introduction}

One-dimensional cadmium sulfide nanostructures are one of the important material of II-VI semi- conductor compounds because it has wide band gap (2.42 eV) and proposed as a potential material for numerous applications in solar cell devices [1], thin film transistors, optoelectronic devices, [2] waveguide [3], electronic devices, photovoltaic cells and optical detectors [4-6], photoconductor

*Corresponding author: M Naziruddin Khan, Department of Physics, Faculty of Science, Islamic University, Madinah, 42351, Saudi Arabia

Accepted: February 20, 2020; Published: February 22, 2020

Copyright: (C) 2020 Naziruddin Khan, et al. This is an open-access article distributed under the terms of the Creative Commons Attribution License, which permits unrestricted use, distribution, and reproduction in any medium, provided the original author and source are credited.

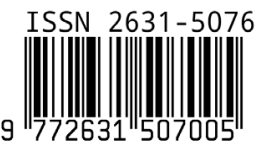

Naziruddin Khan et al. Int J Metall Met Phys 2020, 5:046 
[7], logic gate [8]. Development of new materials by exploring CdS nanostructures with combination of different metals has constituted a promising candidate in this field. Some studies have been attempted on nano-scale semiconductors composites with metals to comprise the surface modified metals and to construct new tailored materials for electronic and photonic properties [9-11]. On other hand, the photocatalysis with semiconductor materials are attracted due to its great potential application for environmental remediation, especially in the decontamination of air and wastewater [12]. Because the photocatalysis is considered as one of new strategies to ease the difficulties by producing renewable fuels (such as hydrogen, methanol and methane) and degrading and mineralizing toxic pollutants $[13,14]$. In fact, CdS have been attracted among the semiconductors, as a potential material because of its cubic or hexagonal crystalline structures [15]. Extensive studies on pure CdS as a visible-light-driven photocatalyst for the degradation of organic pollutants and $\mathrm{H}_{2}$ production were extensively reported $[16,17]$. However, optical, emission and non-linear optical properties [18-22] of metal doped semiconductor nanocomposites were reflected as an important parameter for photocatalytic effect [10], charge dynamics [23]. In addition, with the intention of increase in the photocatalytic efficiency of the CdS, work have been reported on the addition of co-catalysts, doping agents and the formation of composites [24,25]. Among the metals, $\mathrm{Mn}^{2+}, \mathrm{Fe}^{2+}$ and $\mathrm{Co}^{2+}$ have been doped in semiconductors nanoparticles and found to be influenced significantly on their electrical, optical and magnetic properties $[26,27]$ due to the behavior of transition metal ions. Moreover, photoconductivity of metal content semiconductor such as Fe composite CdS have been investigated and led steadily to decline [28], because of Fe was acted as a killer centers in photoconductivity. Incorporation of Fe in CdS revealed considerable influence in the band gap, photoluminescence (PL) properties and peak energy upon increasing the Fe content in the films $[29,30]$. Further, few works on the optical properties of $\mathrm{CdS}$ in presence of $\mathrm{Ag}$ were conducted and found decrease in their surface interaction between the two components, structural, emission - and inter-particles separation upon increasing the quantity of silver in the composite [31,32]. On other hand, $\mathrm{Zn}$ was used as an alternative metal to develop a new composite material with $\mathrm{CdS}$ because of having small ionic radius which allows penetrating into CdS crystal lattice [33]. The Zn composite CdS material can improve in electrical and optical properties which is interested for a wider $\mathrm{CdS}$ based window material. Moreover, a proper fabrication of $\mathrm{Zn}$ into the lattice of $\mathrm{CdS}$ may possible to tune its energy gap and lattice parameters, which is an important for solar cells, diodes, sensors and microelectronics applications. In this context, investigation on physical properties of $\mathrm{Zn}$ doped $\mathrm{CdS}$ films with the optical band gap upon varying $\mathrm{Zn}$ content have been recently reported by $[34,35]$. Therefore, photocatalytic properties of metal composites semiconductor quantum dots such as CdS is highly interested since inclusion of the metals/metal ions to semiconductors can modify the photophysical behavior and photochemical reactivity $[36,37]$. Moreover, metals can influence the surface properties by creating a schottky barrier between the metal and semiconductor's surface because of electron trap. Similarly, incorporation transition of metal ions in semiconductor can improve the charge separation; the trapping of electron with inhibits electron-holes recombination and induces interfacial charge transfer [38,39]. In fact, the advantage of metal doped semiconductor has a larger potential difference between the conduction band of the semiconductor and the Fermi level of the metal which facilitates the electron transfer between the semiconductor and the metal [40]. Hence, a suitable material that can transform the properties of a photocatalyst may possibly be produced by the metal nanocomposites semiconductors. Although many works on the different properties of metals doped semiconductors have been reported, to best of our knowledge, comprehensive coverage studies on the optical and photo-catalytic properties of metals incorporated into CdS are still limited. Therefore, our present studies aimed on the accommodation of different metals (Fe, Ag, Zn) with CdS nanoparticles and to characterize their structural, optical, $\mathrm{PL}$ along with photocatalytic properties under different conditions. The comparison studies among $\mathrm{Fe}, \mathrm{Ag}$ and $\mathrm{Zn}$ doped $\mathrm{CdS}$ on different parameters were systematically done.

\section{Materials synthesis}

All chemical reagents used in the preparation of materials were highly pure with analytical grade and used as received. The reagents used in exper- 
imental have been procured from Sigma, Aldrich and Merck Company such as Cadmium nitrate tetrahydrate-99.99\% (Merck), Ferric nitrate $\geq 99.99 \%$, Silver nitrate $\left(\mathrm{AgNO}_{3}\right)$ 99.9\% (Sigma-Aldrich) and Zinc acetate-99.99 (Sigma). The obtained materials from preparation were produced using simple chemical precipitation method. The synthesize process to obtain different metal doped quantum dots have been adopted as below.

\section{Fe-doped Cds QDs}

To obtain iron (Fe) content $\mathrm{CdS}$ quantum dots, cadmium nitrate $\left(\mathrm{Cd}\left(\mathrm{NO}_{3}\right)_{2} \cdot 4 \mathrm{H}_{2} \mathrm{O}\right)$ and ferric nitrate $\left(\mathrm{Fe}\left(\mathrm{NO}_{3}\right)_{3} .9 \mathrm{H}_{2} \mathrm{O}\right)$ solution were used in the process. A known quantity of cadmium and ferric nitrate solution was taken and mixed with stirring for $1 \mathrm{hr}$ at room temperature. For the Fe-doped CdS nanocrystals, $0.98 \mathrm{M}$ cadmium chloride, $1 \mathrm{M}$ sodium sulphide, $0.02 \mathrm{M}$ ferrous sulphate and 50 $\mathrm{m}$ MME solution were used. The $0.98 \mathrm{M}$ cadmium chloride solution, $50 \mathrm{~m}$ MME solution and $0.02 \mathrm{M}$ ferrous sulphate solution were mixed. Then, $1 \mathrm{M}$ sodium sulfide $\left(\mathrm{Na}_{2} \mathrm{~S}\right)$ solution was added into the above solution and continued stirring for $2 \mathrm{~h}$. Yellowish orange particles were formed after the inclusion of the $\mathrm{Na}_{2} \mathrm{~S}$ solution. The precipitate products were refined by using double distilled water and then separated the particles with centrifuge at $6000 \mathrm{rpm}$ for about $15 \mathrm{~min}$. Subsequently, the resulting particles were washed by MilliQ water and methanol through multiple cycles in centrifuging and then dried in air to produce the powders.

\section{Ag-doped CdS QDs}

In the process, Ag cationic solution was taken as a source of $\mathrm{Ag}$. The cationic solution was used with the $0.1 \mathrm{M}$ of cadmium nitrate tetrahydrate $\left(\mathrm{Cd}\left(\mathrm{NO}_{3}\right)_{2}\right)$ (Merck; 99.99\%) and silver nitrate $\left(\mathrm{AgNO}_{3}\right)$ (Sigma-Aldrich; 99.9\%). The mixture of $0.1 \mathrm{mM}$ cadmium nitrate and $0.6 \mathrm{mM}$ thioglycolic acid was prepared with $100 \mathrm{~mL}$ of doubly de-ionised water and stirred for $30 \mathrm{~min}$. An appropriate volume of $\mathrm{AgNO}_{3}$ solution at $1 \mathrm{mM}$ concentration was added into the above solution under stirring. This final mixture was put into stainless steel autoclave of a Teflon-lined of $100 \mathrm{~mL}$ capacity and preserved at $120-180{ }^{\circ} \mathrm{C}$ for hours. Then, the solution was cooled down at room temperature to attain materials. The materials were separated using centrifuge and washed as a minimum 3 times with distilled water, alcohol and then dried in air at $80-100{ }^{\circ} \mathrm{C}$ for about $10-12 \mathrm{hr}$.

\section{Zn-doped Cds QDs}

The $\mathrm{Cd}\left(\mathrm{CH}_{3} \mathrm{COO}\right)_{2}$ (cadmium acetate), $\mathrm{Zn}(\mathrm{CH}$ $\left.{ }_{3} \mathrm{COO}\right)_{2}$ (Zinc acetate) and $\mathrm{NH}_{2} \mathrm{CSNH}_{2}$ (Thiourea) were involved to synthesize the $\mathrm{Zn}$-content CdS QDs. The above three reagents were initially dissolved in 80 $\mathrm{mL}$ of distilled water. Then, the three solutions of cadmium, zinc acetate and thiourea were mixed in a beaker with stirring continuously for about 10$15 \mathrm{~min}$ at room temperature. Then stirred solution was transferred into a stainless steel autoclave of a $100 \mathrm{~mL}$ Teflon-lined capacity and preserved at 180 ${ }^{\circ} \mathrm{C}$ for few hours. After cooling down to room temperature slowly, yellowish particles were formed and isolated through centrifugation. After washing the yellowish products with distilled water as well as alcohol and then kept at $80^{\circ} \mathrm{C}$ to dry for about $10 \mathrm{~h}$.

\section{Experimental Details}

The phase purity with crystal structure of undoped and metals-doped QDs were evaluated by XRD (PanAnalytic X'Pert Pro) using $\mathrm{Cu}-\mathrm{K}_{\alpha}$ radiation ( $\lambda=0.15405 \mathrm{~nm}$, at $45 \mathrm{kV}$ and $40 \mathrm{~mA}$ ). The XRD data were collected in the $2 \theta$ range of 15 to $75^{\circ}$ at a scan rate $0.02 / \mathrm{s}$. TEM images and energy-dispersive X-ray (EDX) were taken in a JEOL $2100 \mathrm{~F}$ transmission electron microscope. For TEM measurement, a small amount of the CdS and metals doped CdS QDs solution was prepared in methanol, and then a drop on a carbon film with 300 mesh Cu grid. The absorption spectra of the samples were collected in the 200-900 $\mathrm{nm}$ spectral range at $0.5 \mathrm{~nm}$ resolution using a NIR-UV-Visible spectrophotometer, V679 Jasco. The photoluminescence spectra were recorded with Lumina fluorescence spectrometer, Thermo. The infrared spectra of the samples were measured in a FT-IR spectrometer, Parkin Elmer.

The photocatalytical activity of undoped and metals doped CdS nanocomposite with MB dye was investigated using some quartz cuvettes under the exposure of sunlight. About $2.5 \mathrm{~mL} \mathrm{MB}$ dye solution was taken and mixed with desired amount of catalysts. Before exposure under sunlight, the mixture solution was ultra-sonicated to homogeneously distribution in a dark place for $30 \mathrm{~min}$ to establish an adsorption-desorption equilibrium. The concentration of $M B$ in the solutions was established by referring to an absorption-concentration standard curve that was 
determined by measuring the optical absorption of methylene blue at $663 \mathrm{~nm}$. The degradation was monitored by measuring the absorbance of the solutions.

The degradation efficiencies of the MB dye are estimated by the following equation;

$$
\text { Degradation }(\%)=\frac{C_{o}-C}{C_{o}} \times 100
$$

Where $C_{0}$ represents the concentration of the dye before illumination, $C$ denotes the concentration of dye after a certain irradiation time, respectively.

\section{Results and Discussion}

\section{Structural analysis}

The crystallite sizes, content of impurity and structural properties were evaluated using X-ray diffraction (XRD). The typical XRD patterns of undoped and metals ( $M=\mathrm{Zn}, \mathrm{Ag}$ and Fe) doped $\mathrm{CdS}$ quantum dots are shown in Figure 1. The patterns indicate that all composite samples exist the cubic phase of CdS structures, comprising to (111), (220), and (311) lattice planes as compared to the data from JCPDS file no. 42-1411. No additional peaks related to ( $\mathrm{Zn}$ and $\mathrm{Fe}$ ) metal ion is observed which indicates that the addition of $\mathrm{Zn}$ and $\mathrm{Fe}$ do not make change the crystal structure. The pattern of Ag composite CdS QDs exhibits at $38.6 \mathrm{~nm}$ which is indexed to the (111) planes of fcc structure (JCPDS file no. 65-2871). Moreover, the peak positions shift to lower angle, which suggests that the metals $\mathrm{M}(\mathrm{Fe}, \mathrm{Zn}$, and $\mathrm{Ag})$ are well co-existed with the $\mathrm{CdS}$ lattice. In addition, the average crystallite size was

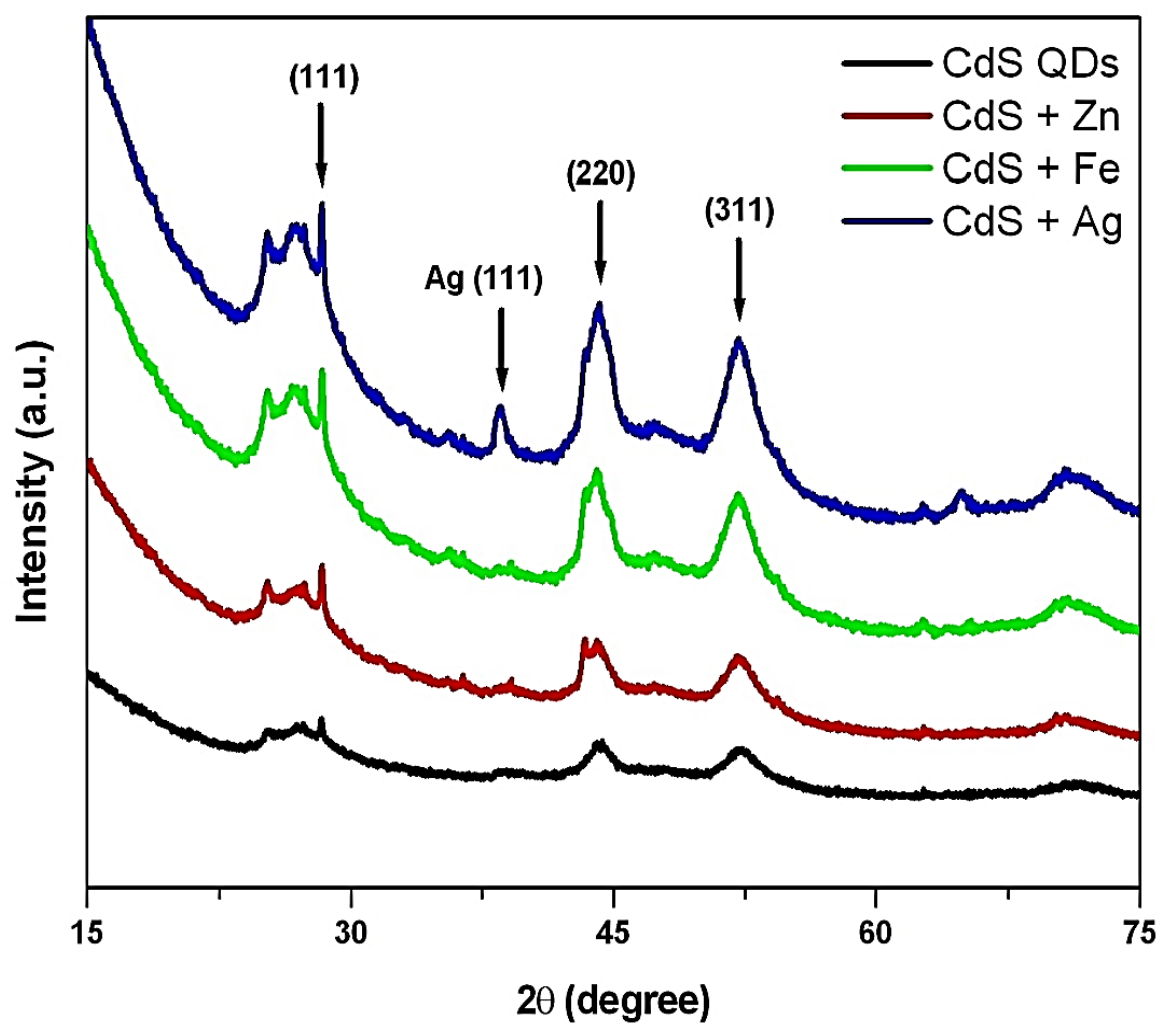

Figure 1: Powder X-ray diffraction patterns of undoped and metals doped CdS quantum dots.

Table 1: The average crystallite size for undoped and metals doped CdS.

\begin{tabular}{|l|l|l|l|l|}
\hline Composition & $\begin{array}{l}\text { Crystallite size by TEM } \\
(\mathbf{n m})\end{array}$ & $\begin{array}{l}\text { Crystallite size by XRD } \\
(\mathbf{n m})\end{array}$ & Band gap (eV) & $\begin{array}{l}\text { Degradation rate } \\
\left(\mathbf{m i n}^{-1}\right)\end{array}$ \\
\hline CdS & $3 \pm 1.7$ & $3.2 \pm 1.8$ & 3.64 & 0.0426 \\
\hline CdS + Ag & $3.2 \pm 1.4$ & $3.5 \pm 1.2$ & 3.43 & 0.0212 \\
\hline CdS + Fe & $3.6 \pm 1.3$ & $4.1 \pm 1.1$ & 3.50 & 0.0201 \\
\hline CdS + Zn & $3.9 \pm 1.6$ & $4.4 \pm 1.3$ & 3.35 & 0.0034 \\
\hline
\end{tabular}


estimated by taking full width at half maximum of the intense diffraction peak using the Debye Scherrer equation [41].

$$
D=k \lambda / \beta \cos \theta
$$

Where $k$ is a shape factor of the particle, $\lambda$ and $\theta$ are the wavelength and the incident angle of the X-rays, respectively. The average crystallite size for undoped and metals doped $\mathrm{CdS}$ are listed in Table 1. The average crystallite sizes of $\mathrm{CdS}, \mathrm{Zn}$, $\mathrm{Fe}$, and $\mathrm{Ag}$ doped CdS QDs are obtained approximately as $3.2,4.4,4.1$ and $3.5 \mathrm{~nm}$ respectively. It is observed that the crystallite size increases as the metals added in CdS and dependent on the type of metals. The intensities of diffraction spectra of metals-doped CdS significantly incline as compared to that of pure CdS, suggesting the increase of crystallinity of the composite as shown in Figure 1. It can be seen that the crystallite size value of $\mathrm{Ag}$ doped $\mathrm{CdS}$ is considerably larger than the size value of $\mathrm{Fe}$ and $\mathrm{Zn}$ doped $\mathrm{CdS}$. The variation of crystallite size with different metals doping into CdS may attribute to difference in lat- tice parameter values and ionic radius of $\mathrm{Ag}, \mathrm{Fe}$ and $\mathrm{Zn}$. Incorporation of different metal ions into the CdS lattice can cause the lattice volume of $\mathrm{Cd}$ ions since the ionic radius of $\mathrm{Cd}^{2+}$ is different from the ionic radius of $\mathrm{Ag}, \mathrm{Fe}$ and $\mathrm{Zn}$ [42].

\section{Morphological analysis}

The crystal and morphological structures of $\mathrm{Fe}, \mathrm{Ag}$ and $\mathrm{Zn}$-doped CdS QDs was characterized by TEM images. Analysis of CdS QDs indicates that majority of particles are spherical with the average sizes of around $3 \mathrm{~nm}$ as displayed in Figure 2a. When the Fe nanoparticles combined with CdS QDs, some spherical particles of dark contrast are existed with around $3.6 \mathrm{~nm}$ which ascribe to Fe nanoparticles as seen in Figure 2b. As clearly seen that CdS nanoparticles have crystalline in nature and uniformly distributed closely together with Fe particles of about more or less $3.6 \mathrm{~nm}$ in diameter. But micrographs of Ag doped QDs shows spherical particles with defects and have an average diameter of about 3.2 $\mathrm{nm}$ as shown in Figure 2c. On the other hand, $\mathrm{Zn}$
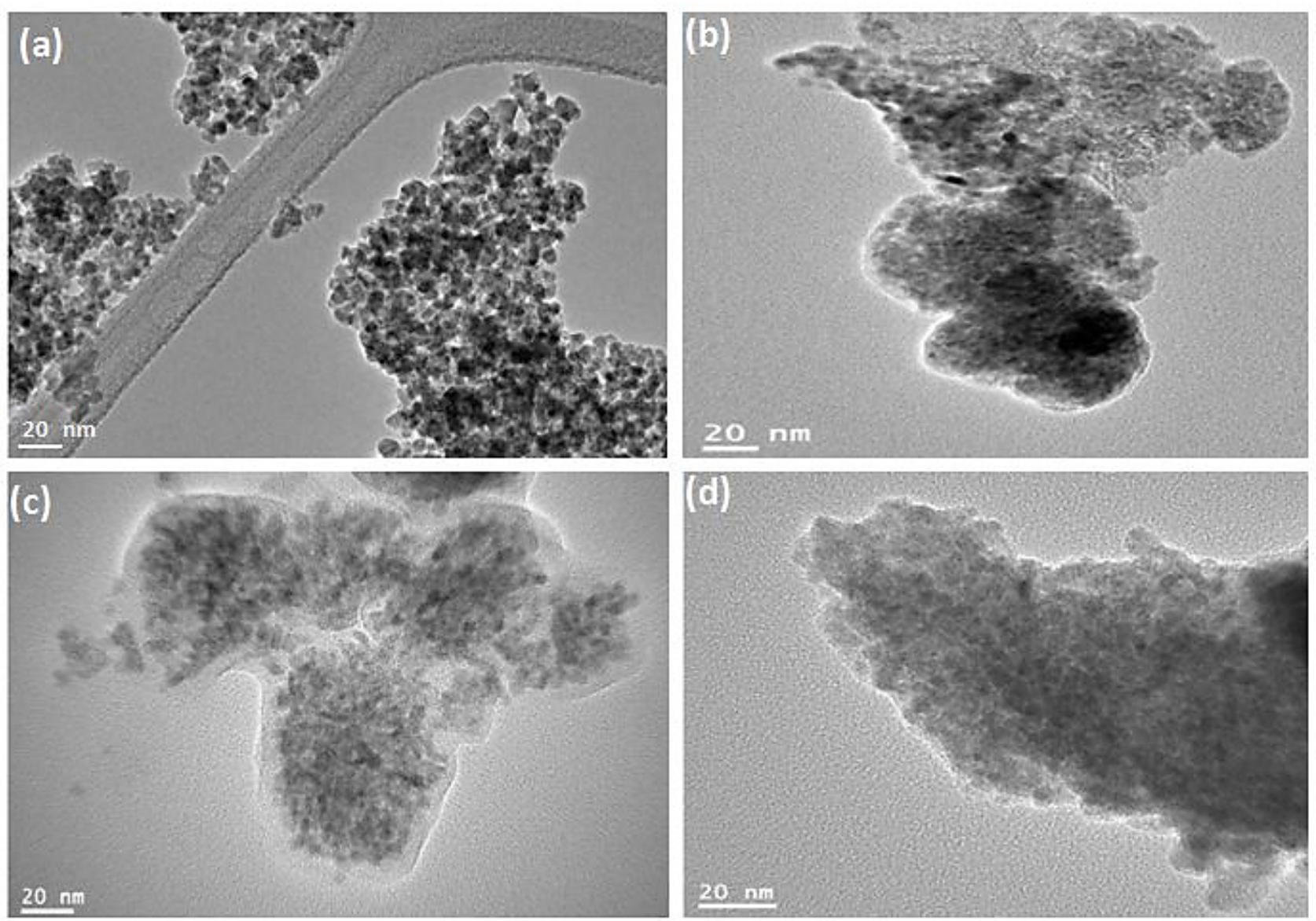

Figure 2: TEM images of: a) Undoped; b) Fe; c) Ag and d) Zn doped CdS quantum dots. 

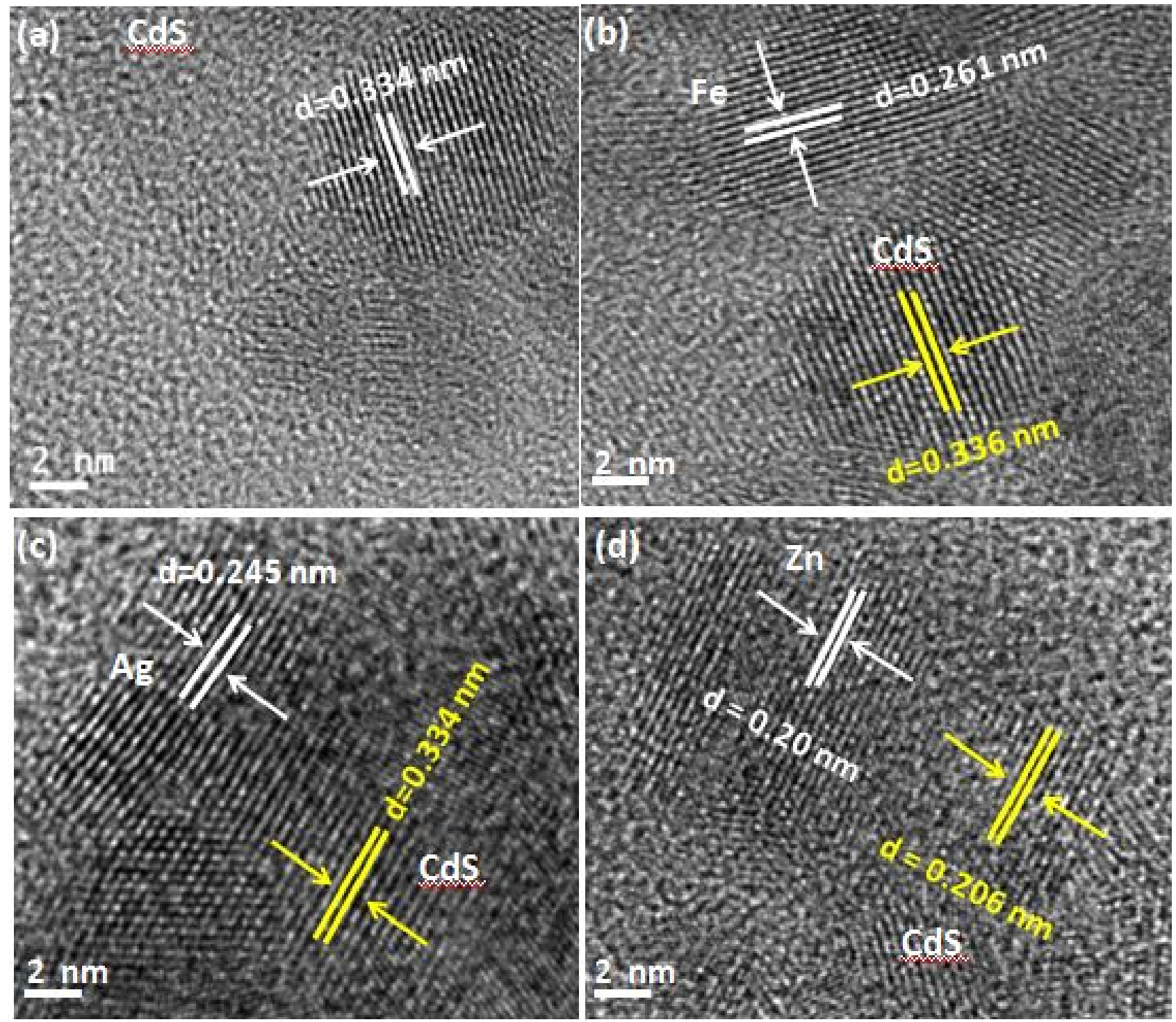

Figure 3: HRTEM image of: a) Undoped; b) Fe; c) Ag and d) Zn doped CdS quantum dots.

content CdS QDs shows roughly spherical particles and mono distribution with an average diameter of around $3.9 \mathrm{~nm}$ appearing to be high crystalline quality as shown in Figure $2 \mathrm{~d}$. It is evident that the particle sizes observed by TEM are approximately close with the values of crystallite sizes of XRD results. The variation of particles size of metals doped CdS are observed to be dependent on type of metals and followed as same the trend of XRD. The high resolution images of pure and metals-doped CdS QDs are presented in Figure $3 a$, Figure $3 b$, Figure $3 c$ and Figure $3 d$. As seen in the micrograph images, the inter planar spacing (d) between the two consecutive planes in the lattice fringes is estimated to be around $0.334 \mathrm{~nm}$, which is consistent with the known values for the (111) plane of CdS as seen in Fig- ure 3a. The inter-planar spacing of Fe-doped CdS QDs is found to be $0.261 \mathrm{~nm}$ on Fe planes as seen in Figure $3 b$ and Figure $3 c$ illustrates a high resolution image of $\mathrm{Ag}$ nanoparticle with inter planar fringe of $0.245 \mathrm{~nm}$ relating to the $d$ spacing of the fcc $\mathrm{Ag}$ (111) crystal plane. In addition, the inter-planar fringe of $\mathrm{Zn}$ nanoparticle is obtained about $0.20 \mathrm{~nm}$, which closes to the $d$ spacing of the (001) plane as shown in Figure $3 d$. The elemental mapping and the presence of elements in composition were measured by energy-dispersive X-ray spectrometry (EDAX) with the TEM. The EDAX spectra confirmed the presence of $C d$ and $S$ peaks of pure cadmium sulfide and existence with $\mathrm{Ag}, \mathrm{Fe}$, and $\mathrm{Zn}$ in metal doped nanocomposites as shown in Figure $4 a$, Figure 4b, Figure $4 c$ and Figure $4 d$. The peaks of $C$ and $\mathrm{Cu}$ are 

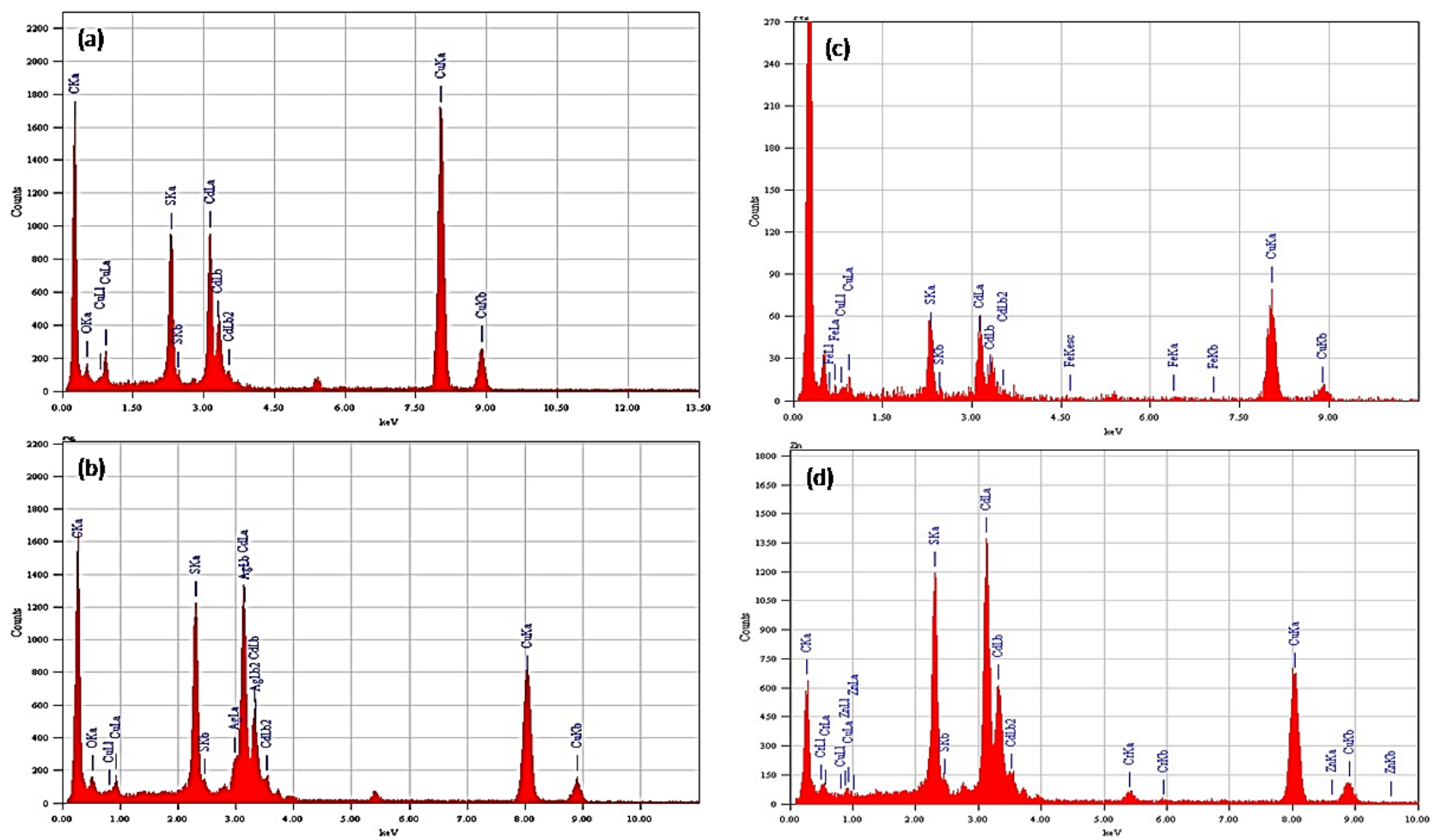

Figure 4: EDAX spectra of: a) Undoped; b) Ag; c) Fe and d) Zn doped CdS quantum dots.

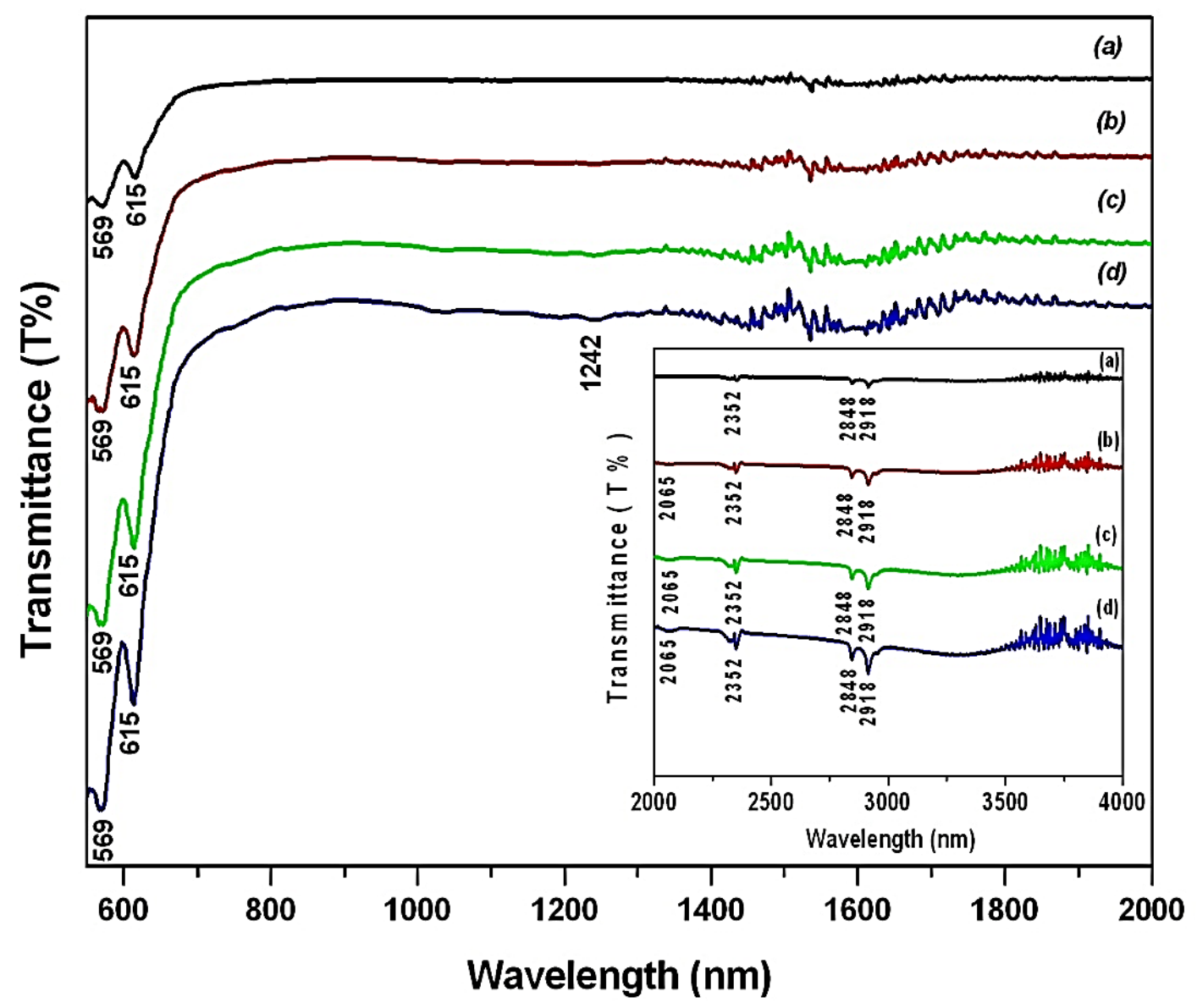

Figure 5: FTIR spectrum of: a) Undoped; b) Zn; c) Fe and d) Ag doped CdS quantum dots. 
from carbon-coated copper grid which used in the measurement as seen in Figure 4.

Further, molecular structure of the undoped and metals doped CdS QDs were investigated in the mid IR region. The IR spectra suggest that interaction between pure CdS and metals are confirmed and formed the nanocomposites. Figure 5 shows the FTIR spectra of CdS and metals (Fe, $\mathrm{Ag}, \mathrm{Zn}$,) doped $\mathrm{CdS}$ nanoparticles over the range of $500-4000 \mathrm{~cm}^{-1}$. The IR spectra of composite samples were recorded using ATR method. For metals-doped CdS samples, the absorption peaks observe around at 569 and $615 \mathrm{~cm}^{-1}$ are in accordance with $\mathrm{O}-\mathrm{H}$ bending vibration of $\mathrm{CdS}$ [43]. No significant changes at these two feature due to metals. The vibrational features appeared around $1390 \mathrm{~cm}^{-1}$ and $2065 \mathrm{~cm}^{-1}$ are related to the $\mathrm{C}-\mathrm{N}$ and $\mathrm{C}-\mathrm{N}$ stretching vibrations on the surface of the CdS nanoparticles. The peak observed at 2848 and $2918 \mathrm{~cm}^{-1}$ is possibly in accordance with the anti-symmetric and symmetric vibrations of the $-\mathrm{CH}_{2}$ groups [44]. The broad feature centered at $3422 \mathrm{~cm}^{-1}$ is in accordance with $\mathrm{O}-\mathrm{H}$ stretching vibration of water molecules. Over all, the relative intensity of all metals doped CdS increases as compared to the intensity of pure CdS QDs which is suggesting the improvement of crystallinity in CdS due to involvement of metals. As clearly seen in Figure 4, increasing in relative intensity of metal doped CdS is corresponding with the nature of metals.

\section{Absorption analysis}

The behavior of optical band gaps (Eg) for the metals doped CdS QDs was conducted using their fundamental absorption spectra. The typical comparison absorption spectra between the undoped and metals doped QDs is displayed in Figure 6a. The absorption peak of CdS QDs at 267 $\mathrm{nm}$ is observed which is attributed as due to the exciton peak of CdS [45]. Absorption peak at 267 $\mathrm{nm}$ shows broadening in the case of metals doped $\mathrm{CdS}$ as compared to pure $\mathrm{CdS}$, which may possible that the exciton peak energies in the doped sample are distributed over wide energies. The absorption peaks of undoped and metals ( $\mathrm{Zn}, \mathrm{Fe}$ and $\mathrm{Ag}$ ) doped CdS QDs are observed with their band edged in the range of (260-300) $\mathrm{nm}$ which

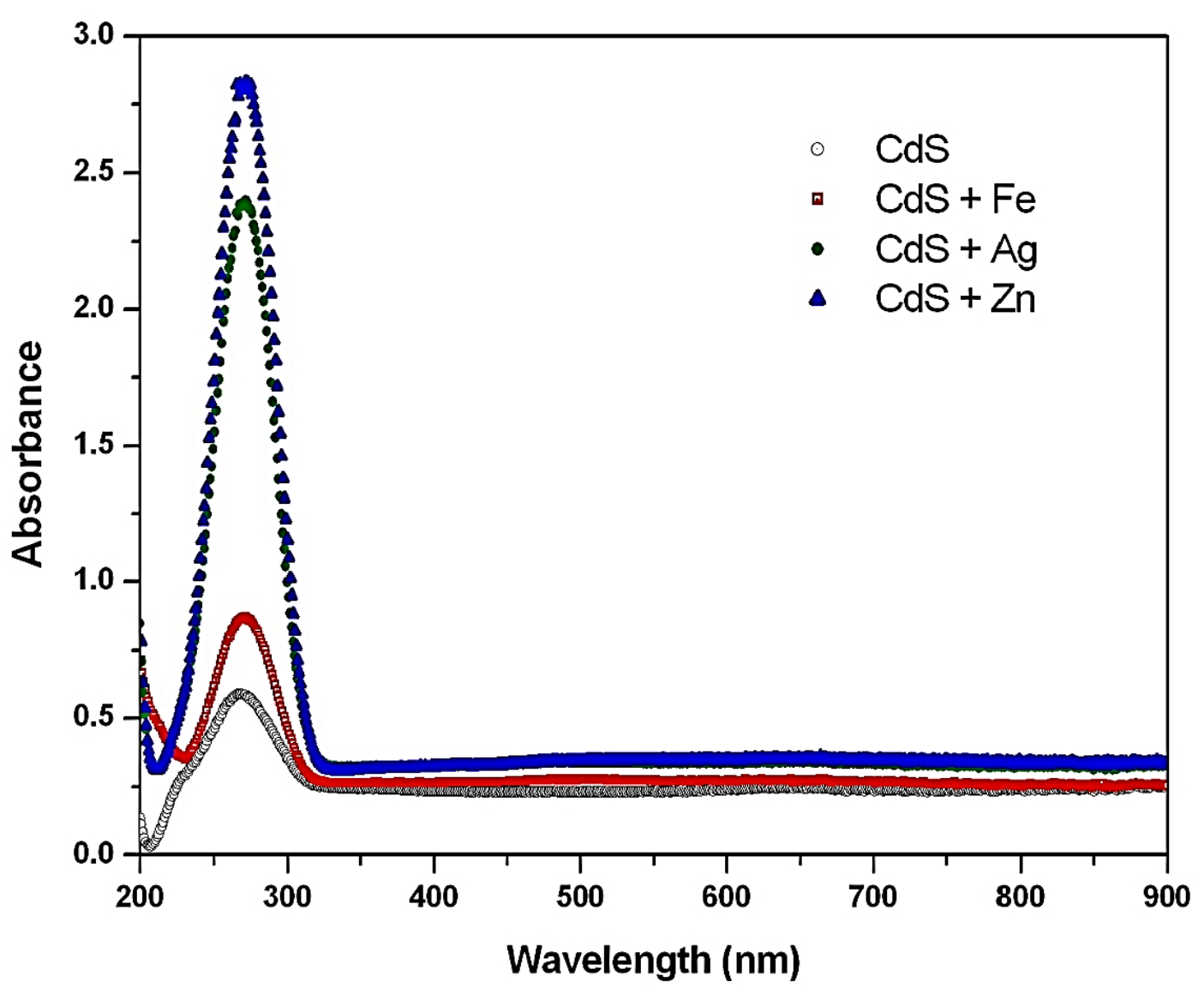

Figure 6a: Absorption spectrum of undoped and metals doped CdS QDs. 


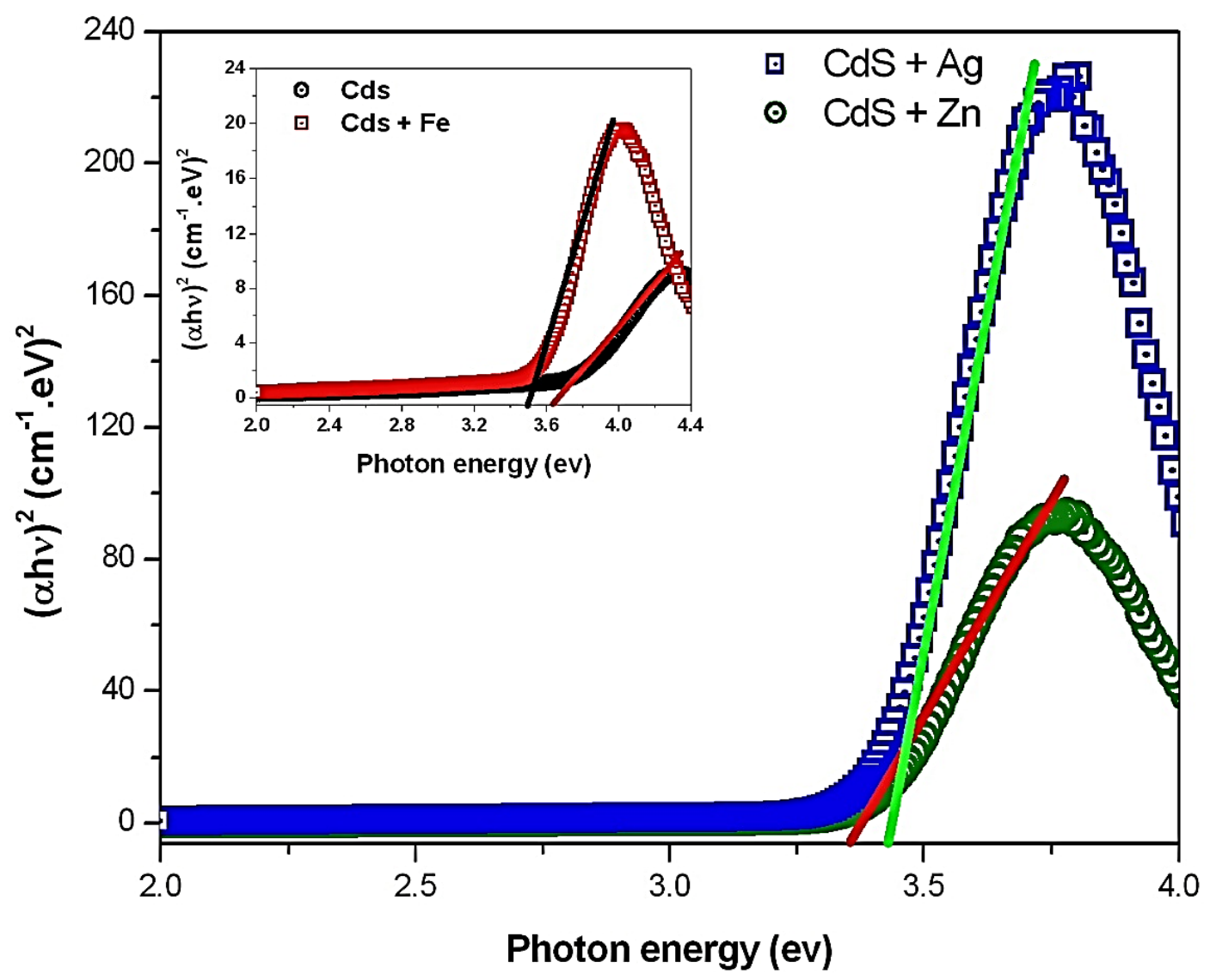

Figure 6b: $(\alpha h v)^{2}$ vs. ev curves of undoped and metals-doped CdS QDs.

significantly shifted as compared to that of CdS bulk material. The absorbance of the metals doped $\mathrm{CdS}$ are increased from the absorbance of pure CdS. The absorption peak positions of doping metals, namely silver ( $\mathrm{Ag})$, iron (Fe) and $\mathrm{Zn}$ are observed at 270, 272 and $273 \mathrm{~nm}$ which are all very slightly red-shifted as compared with the absorption of $\mathrm{CdS}$ at $267 \mathrm{~nm}$. These pattern were observed with metals co-doped CdS quantum dots [46-48]. Also a slightly red-shift has been observed in the absorption edge on doping the nanoparticles with $\mathrm{Ag}$. And significant broadening or shift in the absorption band indicates that the interaction of the metal atoms with the CdS is strong. The band gap of QDs and metals doped has been determined from Tauc equation. The estimated values of band gap of the undoped and metals doped QD is shown in Figure 6b. The gap values of the $\mathrm{Ag}, \mathrm{Fe}$ and $\mathrm{Zn}$ doped are less than that of the QDs value of $3.64 \mathrm{eV}$. Shifting of band gaps when metals are included in CdS QDs may possibly be due to the increment in the carrier concentration along with the formation of defect levels in the band gap. Using the Tauc re- lation, the values of optical band gap have been determined as described in [49].

$$
(\alpha h v)^{m}=B\left(h v-E_{g}\right)
$$

Where $\alpha$ is the absorption coefficient can be obtained from the relation ( $\alpha=A / D$; $A$ is the $a b$ sorption and $D$ is the thickness of the cuvette), Eg is the band gap, B is a constant which does not depend on photon energy. The value of $m$ is considered either 2 for direct transition or $1 / 2$ for an indirect transition. The band gaps of undoped and metals (Fe, Ag and $\mathrm{Zn}$ ) doped nanoparticles can be obtained by plotting a graph between $(\alpha h v)^{2}$ and $\mathrm{hv}$, then extrapolating the straight line to the X-axis as shown in Figure $6 \mathrm{~b}$. The estimated values of direct band gap for $\mathrm{Fe}, \mathrm{Ag}$, and $\mathrm{Zn}$-doped CdS QDs are found to be about $3.50 \mathrm{eV}, 3.43 \mathrm{eV}$ and $3.35 \mathrm{eV}$ respectively, which is lower than that of CdS QDs (3.64 eV). In fact, such reduce of the optical band gap of metal composite QDs may assume to originate from the optically active sub-levels formed by doping [50-52], increase in size of crystallites and modification of the lattice symmetry that lead to defect centers within the lattices. Such parameters 

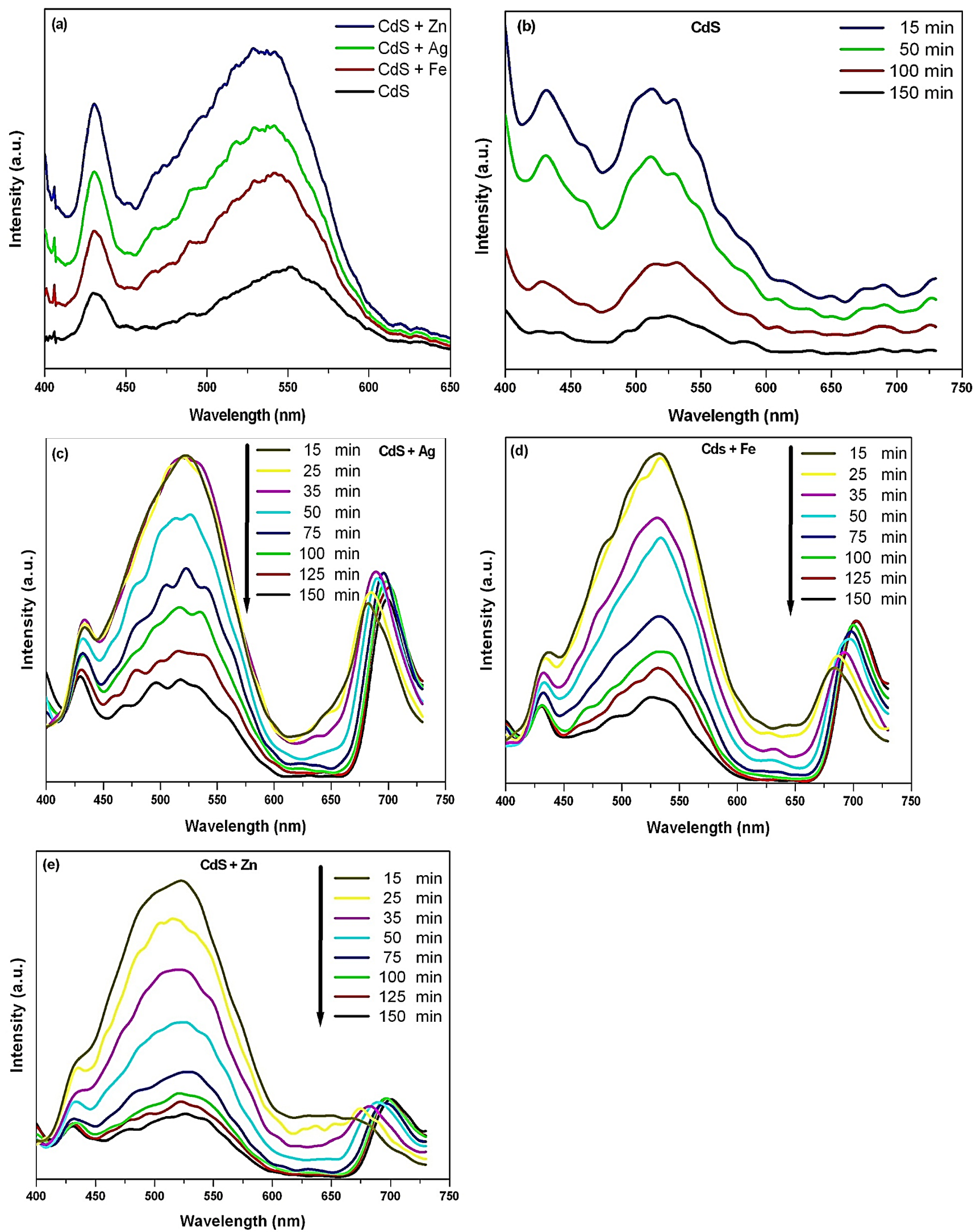

Figure 7: Photoluminescence spectra of: a) Undoped and metals doped CdS QDs and Time dependent PL spectra of: b) Undoped; c) Ag; d) Fe and e) Zn doped CdS under visible light. 
can make strong influential in the band structure with great change in properties of CdS QDs.

\section{Photoluminescence analysis}

The effect on energies and dynamics of photo-generated charge carriers as well as nature of the emitting states were studied using photoluminescence (PL) property of undoped and metal doped CdS. Figure 7a shows the PL spectra of undoped and metals-doped CdS QDs with the peak centred at $550 \mathrm{~nm}$ with a shoulder $430 \mathrm{~nm}$. In fact, at lower absorption wavelength as an excitation wavelength $270 \mathrm{~nm}$ was taken, a broad emission centered at $550 \mathrm{~nm}$ from present samples. It has been reported that feature of broad emission is enhanced by the recombination of shallow region trapped electron-hole pairs and/ or excitons [53]. Indeed, CdS QDs fundamentally consist a broad emission band at $521 \mathrm{~nm}$ along with a shoulder at $430 \mathrm{~nm}$. The broad and shoulder emission are assumed to be from carrier recombination on surface states and excitonic emission of CdS nanocrystals [54] respectively. When the metals included in CdS, no significant changed at the position of excitonic emission is observed, but the broad emission slightly shifts toward shorter wavelengths as compared to that of pure CdS. In addition, the width of the emission bands also becomes more broaden than that of pure CdS. The effect on emission band of metals doped CdS may attribute to the metals content. The emergence of larger in width indicates the overlap of metals-related luminescence with the surface state of undoped CdS. Interestingly, upon doping of metals in $\mathrm{CdS}$, the emission intensity significantly increases and dependent on the type of metal. For instance, emission intensity of $\mathrm{Zn}$ doped $\mathrm{CdS}$ is remarkable as compared to that of $\mathrm{Ag}$ and Fe doped $\mathrm{CdS}$ nanocomposite. Thus, significant increasing of emission intensity of $\mathrm{Zn}$ content $\mathrm{CdS}$ could be as due to $\mathrm{ZnS}$ as previously reported [45]. Moreover, enhanced in emission intensity of silver content $\mathrm{CdS}$ may possible to an increased local field by silver surface plasmons as assumed in [55]. Fe doping shows no variation in peak position, it may possible that $\mathrm{PL}$ bands are not associated with Fe ions but with the shallow impurities and native defects in CdS nanoparticles [56].

Two emission bands of CdS QDs are observed when it is combined with dye. The emission peak at $695 \mathrm{~nm}$ is originated from dye and that relates to the fluorescence of molecule from the excited singlet state to its ground state $[57,58]$. Moreover, the time-dependent PL spectra of pure CdS, $\mathrm{CdS}: \mathrm{Ag}, \mathrm{Fe}: \mathrm{CdS}$ and $\mathrm{Zn}: \mathrm{CdS}$ show that the intensities are decreased gradually with increasing irradiation time, indicating an enhancement in nanoparticles as shown in Figure $7 b$, Figure $7 c$, Figure $7 d$ and Figure 7e. When the irradiation time increases, the emission peak of the composite $\mathrm{CdS}$ decreases and reach a state of remain unchanged, with the colors of metal doped solution. The reason may attributes to the absorption property that CdS QDs with the metals ions occupy the lattice with better crystallinity and symmetry. It is possible to reduce in the transition probability that causes to decrease in the emission intensity.

\section{Photocatalytic performance}

To evaluate the influence of different metals doped on the photocatalytic activities of CdS QDs, the absorption spectra of the undoped and metals doped samples by exposing the aqueous solution of $\mathrm{MB}$ dye under visible light at different interval of times was systematically recorded under same condition. The decolorization rate of the samples was noted in terms of change in absorbance. The catalytic efficiency or percentage of decolorization as a function of time under visible light irradiation within the spectral range of $400-800 \mathrm{~nm}$ as shown in Figure 8. Figure 8a shows the typical absorption spectrum of $\mathrm{CdS}$ in MB dye solution. A strong absorbance of MB dye appears at 663.0 $\mathrm{nm}$ which gradually decreases with increasing the UV exposure time and nearly disappeared after $125 \mathrm{~min}$ i.e. there is no absorption peak of $M B$ dye observed after $125 \mathrm{~nm}$ exposure time which may due to the completely photobleaching of methylene blue dye. The decrease in the absorbance indicates the photo-degradation of $\mathrm{MB}$ dye was occurred with the photocatalysts. The degradation efficiency of MB with CdS QDs is $62.81 \%$ at $150 \mathrm{~min}$ of irradiation time under visible light. But, the calculated efficiency values of Ag-CdS, Fe-CdS and $\mathrm{Zn}-\mathrm{CdS}$ nanocomposites are found to be $70.73 \%, 77.77 \%$ and $82.02 \%$ respectively. It is evident from Figure $8 a$ that the degradation efficiency of MB with CdS QDs is obtained as $62.81 \%$ at $150 \mathrm{~min}$ of irradiation time under visible light. The decrease in absorption peak of $M B$ is still observed at 150 min irradiation, when $\mathrm{Ag}$ is involved 


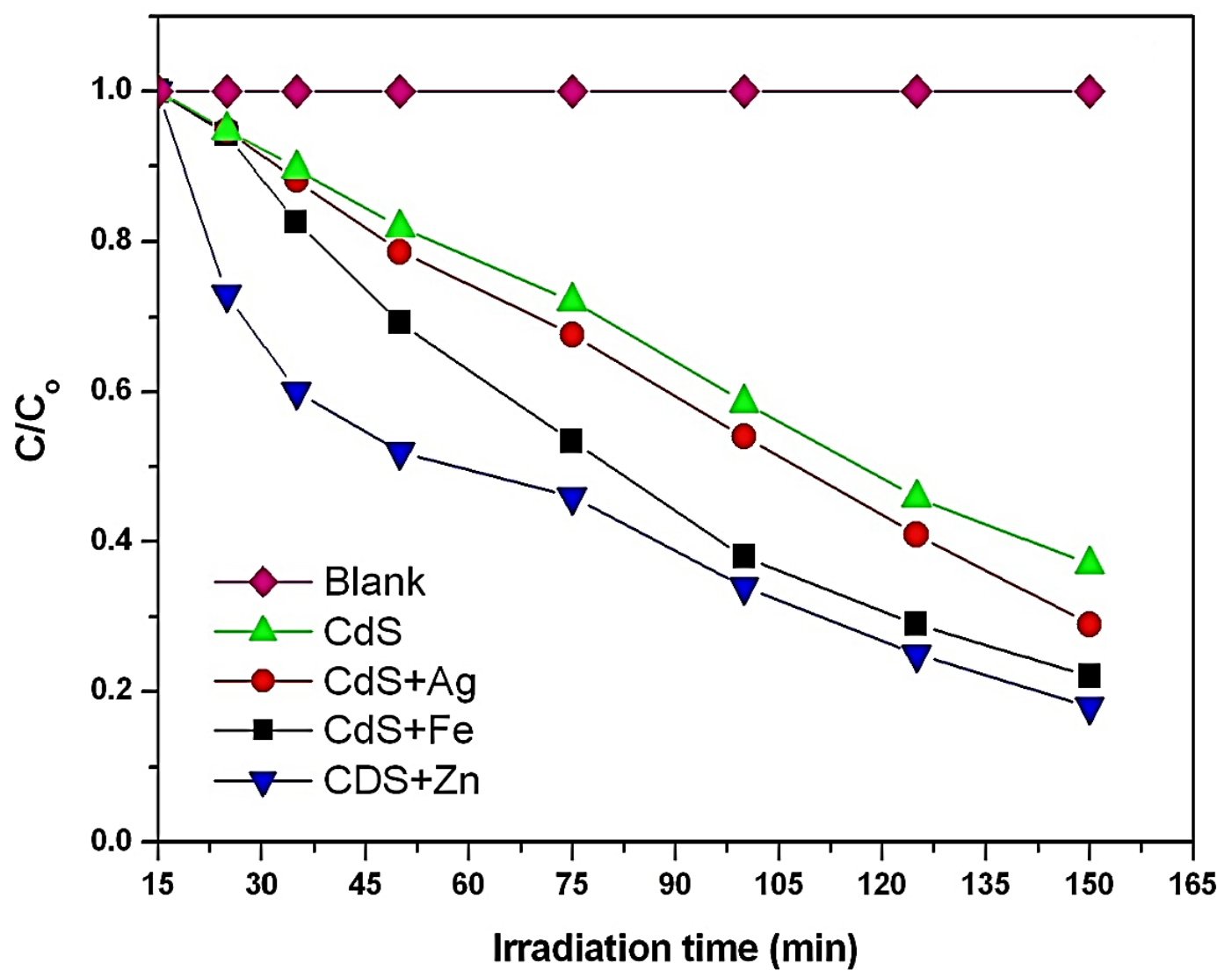

Figure 8: Plots of $C /$ Co versus irradiation times (See Figure S1).

in the solution, which means that the degradation rate enhances when the metals ions included in CdS QDs as shown in Figure 8b. Similar properties of Fe doped CdS NP was observed as higher catalytic degradation as compared to undoped $\mathrm{CdS}$ [47]. On other hand, rate of degradation is slightly faster in case of Fe doped CdS since the peak is disappeared at $150 \mathrm{~min}$ as shown in Figure 8c. Similarly, rate of degradation of MB with $\mathrm{Zn} \mathrm{CdS}$ is more when irradiation time as reach at $150 \mathrm{~min}$ as seen in Figure $8 d$. It is evident from Figure $8 b$, Figure $8 c$ and Figure $8 d$ (see Figure S1) that rate of degradation of $\mathrm{MB}$ under irradiation of visible light depends on the nature of metals. The comparison on the rate of degradation for all metals doped $M B$ is displayed in Figure 8f. As clearly seen in Figure $8 f$, the rate of degradation of $M B$ with $\mathrm{Zn}-\mathrm{CdS}$ is more superior on photocatalytic property than the both $\mathrm{Ag}$ and Fe doped CdS. Moreover, the calculated efficiency values of $\mathrm{Ag}-\mathrm{CdS}, \mathrm{Fe}-\mathrm{CdS}$ and $\mathrm{Zn}$-CdS nanocomposites were found to be $70.73 \%$, $77.77 \%$ and $82.02 \%$ respectively. The degradation efficiency of $\mathrm{Zn}-\mathrm{CdS}$ is much higher than $\mathrm{Ag}$ and Fe doped composite. Present results are supported by previous work [51] that the degradation rate of $\mathrm{MB}$ with Fe content $\mathrm{CdS}$ was caused by the defect sites of metals that can enhance absorption. Doping of $\mathrm{Ag}$ and $\mathrm{Zn}$ in CdS crystal lattice could increase and improve to photo catalytic activity and stability $[52,58]$. The rate of enhancement activity of $\mathrm{Ag}, \mathrm{Fe}$ and $\mathrm{Zn}$ with CdS may influence to degradation rate due to different of transfer of photogenerated electrons from the conduction band of $\mathrm{CdS}$ to metals on the surface. Interestingly, there is no photo-degradation and changed in peak and intensity of MB dye as a function of different time under UV irradiation as displayed in Figure 8f. The enhancement of photocatalytic activity can be attributed to the broaden in absorption band due to the inclusion of metals Figure $3 \mathrm{~d}$ as well as the well recombination of photo-generated electron-hole pairs due to the charge transfer between metals ( $\mathrm{Ag}, \mathrm{Fe} \& \mathrm{Zn}$ ) and CdS QDs. In addition, it is also possible to transfer the electrons from the conduction band to the metal nanoparticles during photo induced which brings about electron sink that lead to impede electron-hole pairs recombination. This recombination of electron-hole pairs 
may lead to form the sites for accumulation of the photo-generated electrons which may help to improve the separation of electrons and holes [59]. In this occurrence, the lower energy level in the conduction band of CdS will be greater than the equilibrium fermi energy level $\left(E_{f}\right)$ of metals composite $\mathrm{CdS}$, during the process, the photo-excited electrons in the conduction band could possible to transfer from CdS to metals nanoparticles. Therefore, it may conclude that metal nanoparticles can act as electron sinks and influence in reducing the recombination of photo-induced electrons and holes which is also a factor of improvement in the photo-catalytic activity [60-62]. In view of environmental pollution issue, organic dyes are found to be often discharged with wastewater into the local environment. An adequate treatment or proper removal of organic dyes from wastewater is still a challenging issue. In fact, the potential dye adsorbents with large-scale in order to exhibit high dye removal rate within a short period of time has been required. Due to the lack of photocatalytic technology to solve the issues, some disadvantages may possible be with prepared photocatalyst such as the low quantum efficiency, low recyclability, low utilization of sunlight lead to low photocatalyst efficiency. Therefore, significant researches still need to advance in order to exhibit a highly photocatalytic efficiency with stable visible light that may able to stimulate into photocatalytic technology.

\section{Conclusion}

Synthesis of CdS QDs and doped with three different metals ( $\mathrm{Fe}, \mathrm{Ag}$ and $\mathrm{Zn}$ ) by a simple chemical precipitation method have been reported. The structural, optical and photo-catalytic properties of metals doped CdS QDs were systematically analyzed by XRD, FTIR, UV-vis, $P L$, and TEM, techniques. The catalytic activity of metals composite CdS and influence of metal on photo-catalytic performance under the sun light was evaluated. XRD and TEM analyses reveal the formation of single phase and increase of average particle size of the metals composite samples. Analysis of absorption band edge and emission properties of metals doped QDs indicates the unusual red-shift and enhancement of emission light as compared to that of pure CdS. The rate of degradation of MB under irradiation of visible light depends on the nature of metals.
Subsequently, photocatalytic performance of Fe, $\mathrm{Ag}$ and $\mathrm{Zn}$ doped $\mathrm{CdS}$ is observed different but $\mathrm{Zn}$ doped CdS QDs exhibits superior as compared to $\mathrm{Ag}$ and Fe doped $\mathrm{CdS}$. Though the present results of metals elements, like $\mathrm{Zn}, \mathrm{Ag}$, and Fe composite CdS reveal a good enhancement in their optical properties as compared to pure CdS, the photocatalytic performance is observed to be depend on the nature of metal. For instance, performance of photocatalytic activity and stability of $\mathrm{Zn}$ doped $\mathrm{CdS}$ shows superior in comparison with the performance of $\mathrm{Ag}$ and Fe doped CdS. Therefore, it may conclude that a proper study on different metals including Zn metal doped CdS will be useful to demonstrate and exhibit high tunable optical and photocatalytic properties for applications in technology.

\section{References}

1. Y Kang, D Kim (2006) Well-aligned CDS nanorod-conjugated polymer solar cells. Sol Energy Mater Sol Cells 90: 166-174.

2. M Thambidurai, N Muthukumarasamy, S Agilan, N Murugan, SN Arul, et al. (2010) Studies on optical absorption and structural properties of Fe doped CdS quantum dots. Solid State Sci 12: 1554-1559.

3. R Agarwal, CJ Barrelet, CM Lieber (2005) Lasing in single cadmium sulfide nanowire optical cavities. Nano Lett 5: 917-920.

4. N Romeo, G Sbervegbieri, L Taricone (1977) High conductivity CdS films grown by a simple evaporation method. Thin Solid Films 43: 15-17.

5. E Bertran, A Lousa, M Varela, MV Garcia-Cuenca, JL Morenza (1988) Optical properties of indium doped CdS thin films. Sol Energy Mater 17: 55-64.

6. S Thanikaikarasana, T Mahalingama, S Lee, H Lim, S Velumanid, et al. (2010) Electrosynthesis and studies on cadmium-iron-sulphide thin films. Mater Sci Eng B 174: 231-235.

7. T Gao, Q H Li, TH Wang (2005) CdS nanobelts as photoconductors. Appl Phys Lett 86: 173105.

8. RM Ma, L Dai, HB Huo, WJ Xu, GG Qin (2007) High performance logic circuits constructed on single CdS nanowires. Nano Lett 7: 3300-3304.

9. MC Daniel, D Astruc (2004) Gold nanoparticles: Assembly, supramolecular chemistry, quantum-size-related properties, and applications toward biology, catalysis, and nanotechnology. Chem Rev 104: 293-346.

10.CD Grant, TJ Norman Jr, JZ Zhang (2004) Encyclope- 
dia of nanoscience and nanotechnology. In: Nalwa HS, 1: 745.

11. AP Alivisatos (1996) Perspectives on the physical chemistry of semiconductor nanocrystals. J Phys Chem 100: 13226-13239.

12.K Rajeshwar, ME Osugi, W Chanmanee, CR Chenthamarakshan, MVB Zanoni, et al. (2008) Heterogeneous photocatalytic treatment of organic dyes in water and aqueous media. J Photochem Photobiol C Photochem Rev 9: 171-192.

13.A Kudo, Y Miseki (2009) Heterogeneous photocatalyst materials for water splitting. Chem Soc Rev 38: 253-278.

14.C Chen, W Ma, J Zhao (2010) Semiconductor-mediated photodegradation of pollutants under visible-light irradiation. Chem Soc Rev 39: 4206-4219.

15.A Vázquez, T Serrano, B Kharisov, I Gómez (2016) Morphological control of cadmium sulfide nanostructures by electrophoretic deposition. Particuology 24: 73-77.

16.J Zhang, S Wageh, AA Al Ghamdi, J Yu (2016) New understanding on the different photocatalytic activity of wurtzite and zinc-blende CdS. Appl Catal B Environ 192: 101-107.

17.F Vaquero, RM Navarro, JLG Fierro (2016) Evolution of the nanostructure of CdS using solvothermal synthesis at different temperature and its influence on the photoactivity for hydrogen production. Int J Hydrogen Energy 41: 11558-11567.

18.J Yang, HI Elim, Q Zhang, JY Lee, W Ji (2006) Rational synthesis, self-assembly, and optical properties of PbS-Au heterogeneous nanostructures via preferential deposition. J Am Chem Soc 128: 11921-11926.

19.T Mokari, E Rothenberg, I Popov, R Costi, U Banin (2004) Selective growth of metal tips onto semiconductor quantum rods and tetrapods. Science 304: 1787-1790.

20.GH Ma, J He, K Rajiv, SH Tang, Y Yang, et al. (2004) Observation of resonant energy transfer in $\mathrm{Au}$ : $\mathrm{CdS}$ nanocomposite. Appl Phys Lett 84: 4684.

21.J Lee, AO Govorov, J Dulka, NA Kotov (2004) Bio conjugates of CdTe nanowires and Au nanoparticles: Plasmon-exciton interactions, luminescence enhancement, and collective effects. Nano Lett 4: 2323-2330.

22. HS Zhou, I Honma, JW Haus, H Sasabe, H Komiyama (1996) Synthesis and optical properties of coated nanoparticle composites. J Lumin 70: 21-34.

23. Y Wang, M Li, H Jia, W Song, X Han, et al. (2006) Optical properties of $\mathrm{Ag} / \mathrm{CdTe}$ nanocomposite self-orga- nized by electrostatic interaction. Spectrochim Acta A Mol Biomol Spectrosc 64: 101-105.

24.I Majeed, MA Nadeem, M Al-Oufi, MA Nadeem, GIN Waterhouse, et al. (2016) On the role of metal particle size and surface coverage for photo-catalytic hydrogen production: A case study of the $\mathrm{Au} / \mathrm{CdS}$ system. Appl Catal B Environ 182: 266-276.

25.J Chen, F Zhang, YL Zhao, YC Guo, P Gong, et al. (2016) Facile synthesis of CdS/C core-shell nanospheres with ultrathin carbon layer for enhanced photocatalytic properties and stability. Appl Surf Sci 362: 126-131.

26.A Mycielski, P Dzwonkowski, P Kowalski, BJ Kowalski, BA Orlowski, et al. (1986) Location of the Fe $2+(3 \mathrm{~d} 6)$ donor in the band structure of mixed crystals Hg 1-v CdvSe. J Phys C Solid State Phys 19: 3605-3614.

27.A Sarem, BJ Kowalski, BA Orlowski (1990) Optical properties of Fe-based semimagnetic semiconductors. J Phys Condens Mat 2: 8173-8188.

28.B Tripathi, F Singh, DK Avasthi, AK Bhati, D Das, et al. (2008) Structural, optical, electrical and positron annihilation studies of CdS: Fe system. J Alloys Compd 454: 97-101.

29. N Badera, B Godbole, SB Srivastava, PN Vishwakarma, CLS Sharath, et al. (2008) Quenching of photoconductivity in Fe doped CdS thin films prepared by spray pyrolysis technique. Appl Surf Sci 254: 7042-7048.

30.HR Dizaji, M Ghasemian, MH Ehsani (2012) Structural and optical characterization of CdS: Fe thin films prepared by flash Evaporation method. Surf Rev Lett 19: 1250012.

31.A Kumar, V Chaudhary (2007) Optical and photophysical properties of $\mathrm{Ag} / \mathrm{CdS}$ nanocomposites-an analysis of relaxation kinetics of the charge carriers. J Photochem Photobio A Chem 189: 272-279.

32.R Sergio, F Gonzalez, D Berman-Mendoza, R Garcia-Gutierrez, SJ Castillo, et al. (2014) Optical and structural properties of CdS thin films grown by chemical bath deposition doped with Ag by ion exchange. Optik 125: 1533-1536.

33.R Sathyamoorthy, P Sudhagar, A Balerna, C Balasubramanian, S Bellucci, et al. (2010) Surfactant-assisted synthesis of $\mathrm{Cd}_{1-x} \mathrm{Co}_{x \mathrm{~s}}$ nanocluster alloys and their structural, optical and magnetic properties. J Alloy Compound 493: 240-245.

34. M Anbarasi, VS Nagarethinam, AR Balu (2014) Investigations on the structural, morphological, optical and electrical properties of undoped and nanosized Zn-doped CdS thin films prepared by a simplified spray technique. Mater Sci-Poland 32: 652-660. 
35.LS Ravangave, SD Misal, UV Biradar (2013) Effect of Zn content on optical properties and tuning of optical band gap of chemically deposited $\mathrm{Cd}_{1-\mathrm{x}} \mathrm{Zn}_{\mathrm{xs}}$ thin films. Opt Photon Lett 6: 1350006.

36.MR Hoffmann, ST Martin, W Choi, DW Bahnemann (1995) Environmental applications of semiconductor photocatalysis. Chem Rev 95: 69-96.

37.W Choi, A Termin, MR Hoffmann (1994) Effects of metal-ion dopants on the photocatalytic reactivity of quantum-sized $\mathrm{TiO}_{2}$ particles. Angew Chem Int Ed Engl 33: 1091-1092.

38.JM Herrmann, H Tahiri, Y Ait-Ichou, G Lassaletta, AR Gonzalez-Elipe, et al. (1997) Characterization and photocatalytic activity in aqueous medium of $\mathrm{TiO}_{2}$ and $\mathrm{Ag}-\mathrm{TiO}_{2}$ coatings on quartz. Appl Catal B Environ 13: $219-228$

39.A Kumar, S Kumar (1996) Catalytic effect of Ag+ in colloidal CdS-Induced photooxidation of aniline. Chem Lett 8: 711.

40.PV Kamat (2002) Photoinduced transformations in semiconductor-metal nanocomposite assemblies. Pure Appl Chem 74: 1693-1706.

41.T Ahamad, MAM Khan, S Kumar, M Ahamed, M Shahabuddin, et al. (2016) CdS quantum dots: Growth, microstructural, optical and electrical characteristics. Appl Phys B 122: 179.

42.V Narasimman, VS Nagarethinam, K Usharani, AR Balu (2016) Structural, morphological, optical and electrical properties of spray deposited ternary CdZns thin films. Int J Thin Film Sci Tec 5: 17-24.

43.G Chen, B Yi, G Zeng, Q Niu, M Yan, et al. (2014) Facile green extracellular biosynthesis of $\mathrm{CdS}$ quantum dots by white rot fungus phanerochaete chrysosporium. Colloids Surf B Biointerfaces 117: 199-205.

44.A Sabah, SA Siddiqi, S Ali (2010) Fabrication and characterization of $\mathrm{CdS}$ nanoparticles annealed by using different radiations. International Scholarly and Scientific Research \& Innovation 4: 532-539.

45.H Sekhar, YR Kumar, DN Rao (2015) Preparation, structural and linear optical properties of $\mathrm{Zn}$ doped CdS nanopowders. IOP Conf Ser Mater Sci Eng 73: 012079.

46.T Iqbal, G Ara, NR Khalid, M Ijaz (2020) Simple synthesis of Ag-doped CdS nanostructure material with excellent properties. Appl Nanosci 10: 23-28.

47. M Junaid, M Imran, M Ikram, M Naz, M Aqeel, et al. (2019) The study of Fe-doped CdS nanoparticle-assisted photocatalytic degradation of organic dye in wastewater. Appl Nanosci 9: 1593-1602.
48.X Yang, Z Wang, X Lv, Y Wang, H Jia (2016) Enhanced photocatalytic activity of $\mathrm{Zn}$-doped dendritic-like CdS structures synthesized by hydrothermal synthesis. Journal of Photochemistry and Photobiology A Chemistry 329: 175-181.

49.MAM Khan, W Khan (2016) Thickness-dependent structural and optoelectronic properties of $\ln _{2} \mathrm{O}_{3}$ films prepared by spray pyrolysis technique. J Electron Mater 45: 4453-4459.

50.PC Dey, R Das (2017) Photoluminescence quenching in ligand free CdS nanocrystals due to silver doping along with two high energy surface states emission. J Lumin 183: 368-376.

51.R Chauhan, A Kumar, RP Chaudhary (2013) Visible-light photocatalytic degradation of methylene blue with Fe doped CdS nanoparticles. Applied Surface Science 270: 655-660.

52.F Yang, NN Yan, S Huang, Q Sun, LZ Zhang, et al. (2012) Zn-Doped CdS nanoarchitectures prepared by hydrothermal synthesis: Mechanism for enhanced photocatalytic activity and stability under visible light. J Phys Chem C 116: 9078-9084.

53.L Zeiri, I Patla, S Acharya, Y Golan, S Efrima (2007) Raman spectroscopy of ultranarrow CdS nanostructures. J Phys Chem C 111: 11843-11848.

54.P Mandal, SS Talwar, SS Major, RS Srinivasa (2008) Orange-red luminescence from $\mathrm{Cu}$ doped $\mathrm{CdS}$ nanophosphor prepared using mixed Langmuir-Blodgett multilayers. J Chem Phys 128: 114703-114707.

55.K Ray, R Badugu, JR Lakowicz (2006) Metal-enhanced fluorescence from CdTe nanocrystals: A single-molecule fluorescence study. J Am Chem Soc 128: 89988999.

56.J Singh, NK Verma (2012) Synthesis and characterization of Fe-doped CdSe nanoparticles as dilute magnetic semiconductor. J Nov Magn 25: 2425-2430.

57.BS Fujimoto, JB Clendenning, JJ Delrow, PJ Heath, M Schurr (1994) Fluorescence and photobleaching studies of methylene blue binding to DNA. J Phys Chem 98: 6633-6643.

58.MS Smirnov, OV Ovchinnikov, TS Shatskikh, AG Vitukhnovsky, SA Ambrozevich, et al. (2014) Luminescence properties of hydrophilic hybrid associates of colloidal CdS quantum dots and methylene blue. J Lumin 156: 212-218.

59.NE Fard, R Fazaeli, R Ghiasi (2016) Band gap energies and photocatalytic properties of $\mathrm{CdS}$ and $\mathrm{Ag} / \mathrm{CdS}$ nanoparticles for azo dye degradation. Chem Eng Technol 39: 149-157. 
60.U Akpan, B Hameed (2009) Parameters affecting the photocatalytic degradation of dyes using $\mathrm{TiO}_{2}$-based photocatalysts: A review. Hazard J Mater 170: 520529.

61.O Ola, MM Maroto-Valer (2015) Review of material design and reactor engineering on $\mathrm{TiO}_{2}$ photocataly- sis for $\mathrm{CO}_{2}$ reduction. J Photochem Photobio C Photochem Reviews 24: 16-42.

62. MAM Khan, W Khan, M Ahamed, AN Alhazaa (2017) Microstructural properties and enhanced photocatalytic performance of $\mathrm{Zn}$ doped $\mathrm{CeO}_{2}$ nanocrystals. Scientific Reports 7: 12560. 

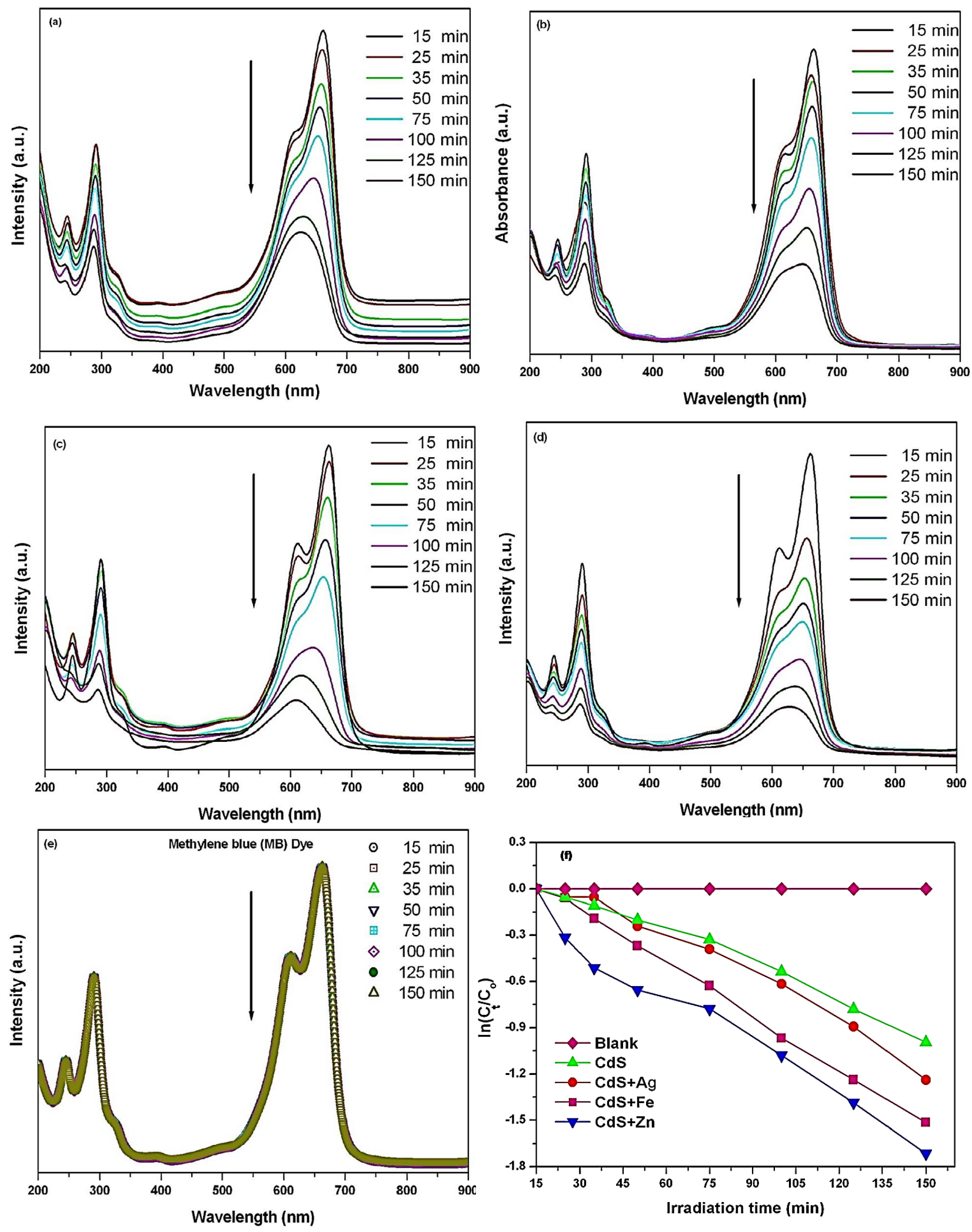

Figure S1: Time-dependent absorption spectra of the methylene blue (MB) aqueous solution: a) Undoped and in presence of: b) Ag doped CdS; c) Fe doped CdS; d) Zn doped CdS QDs aqueous solution; e) Methylene blue $M B)$ as a function of irradiation time; $f)$ Plots of $\ln \left(C_{0} / C_{t}\right)$ versus irradiation times. 